\title{
Paradigma Emergente (Hólon) e o Movimento do Pensamento na Pós-Modernidade
}

\section{Emerging paradigm (Hólon) and the movement of thought on postmodernism}

\author{
Edson Fernandes
}

\begin{abstract}
Edson Fernandes é Doutor em comunicação e Mestre em Educação. Graduado em Publicidade propaganda e Marketing. Professor das Faculdades Integradas Campos Salles. Escritor e autor de livros de literatura e nas áreas de sociologia, política e psicossociologia. É pesquisador. Membro do conselho de revistas científicas e avaliador do INEP/MEC e do Conselho Estadual de Educação de São Paulo. E-mail: profedson@uol.com.br.
\end{abstract}

\section{Resumo}

A complexidade do cenário pós-moderno em seus conceitos e atribuições, referendada por pesquisadores, como Edgar Morin, Gilles Deleuze, Teilhard de Chardin, Ken Wilber e Henri Bergson abre um espaço para o debate das construções do paradigma emergente ou paradigmas emergentes, levando-nos a um processo de reflexão sobre o conceito de hólon, e sua relação com a configuração atribuída à ciência contemporânea. O universo digital é a água que rompeu o dique, e provocou uma inundação de mudanças na sociedade e na cultura, obrigando-nos a rever nossas crenças, valores, princípios e relações sociais. A ciência se tecnologizou e a tecnologia se fez ciência pós-moderna. O ciberespaço é o local de encontros, troca de informações, de convivência social, do pensamento. É o território do nômade, que transita livremente no universo virtual, configurando uma sociedade da tecnocultura, da era da informação, de um paradigma jamais visto antes. Um paradigma que apenas a pós-modernidade poderia concebê-lo em sua complexidade, sem deixar de debater seus limites e fragilidades no pensamento humano.

Palavras chave Paradigma, Hólon, Pensamento Humano, Cibercultura, Universo Digital, Internet.

\begin{abstract}
The complexity of the postmodern scenario in its concepts and assignments, approved by researchers such as Edgar Morin, Gilles Delenze, Teilhard de Chardin, Ken Wilber and Henri Bergson opens a space for discussion of emerging paradigm buildings or emerging paradigms, leading us to a process of reflection on the concept of holon, and its relation to the setting assigned to contemporary science. The digital universe is the water that broke the dyke, and provoked a flood of changes in society and culture, forcing us to revise our beliefs, values, principles and social relations. Science has got technology and technology became postmodern science. Cyberspace is the place of meetings, exchange of information, social coexistence,
\end{abstract}


thought. It is the territory of the nomad, who freely moves in the virtual universe, forming a society of techno-culture, of the information age, a paradigm never seen before. A paradigm which only post-modernity is able to concept on its complex, while discussing its limitations and weaknesses in buman thought.

Keywords: Paradigm, Holon, Human Thought, Cyberculture, Digital Universe, Internet.

\section{Introdução}

A ideia de bólon motiva a reflexão dos elementos que compreendem o imaginário da globalização, da totalização, em boa parte paradoxal ao pensamento do homem pósmoderno, palco de discussões e reflexões pelas áreas do conhecimento.

\section{O bólon pressupõe aspectos,} como: multiplicidade de códigos da linguagem, complexidade sistêmica entre o antagonismo e a conciliação da unidade-todo, movimento entre caos e ordem, processos envolvendo continuidade e descontinuidade, tempo oscilando entre o eterno e o instante fugaz e espaço convivendo entre o local e o global.

\footnotetext{
${ }^{1}$ A Noosfera segundo T. Chardin pode ser considerada como um ecossistema evolutivo do pensamento, formado por produtos culturais, do espírito humano, das linguagens, teorias e conhecimentos; alimentado à medida que pensamos e nos comunicamos. O espírito humano passa da Geosfera, à Biosfera, e então à Tecnosfera, chegando finalmente à Noosfera - desde a ordem dos instintos à complexidade do processo evolutivo cerebral humano abstrato e intuitivo.

$2 \mathrm{O}$ pensamento e o conhecimento atravessaram um longo e complexo percurso histórico durante séculos e
}

O hólon ao manifestar-se na camada da Noosfera ${ }^{1}$ da pós-modernidade (para o conceito de Teilhard de Chardin), compreendida em nossa análise pela linguagem digital e movimentando-se no complexo ambiente do espaço virtual tece cenários socioculturais conectados pela rede de comunicação mundial. Manifesta-se desterritorializando territórios, agenciando o ciberespaço e expressando diferentes formas de representações simbólicas. As linguagens eletrônicas entre usuários nas comunicações virtuais promovem a circulação da camada pensante entre usuários na rede e sistemas inteligentes de máquinas conectadas, produzindo e distribuindo informações no universo das mídias emergentes.

Todavia, o processo histórico do conhecimento $^{2}$ deflagra no paradigma pós-

fundaram crenças, métodos, descobertas, conceitos e princípios científicos, originando a ideia de ciência. Contudo, desde o início do Renascimento, as ideias a respeito do saber e sua aplicabilidade viveram alguns longos e complexos embates, discussões, rupturas e inovações, não apenas em um único campo do conhecimento, mas em inúmeros setores do saber. Sobre este aspecto, Werner Heisenberg analisou a teoria quântica e a estrutura da matéria, a partir dos pressupostos dos atomistas da antiga filosofia grega, do princípio unificador da multiplicidade universal, cuja 
moderno, a passagem de um longo movimento revolucionário desde o Renascimento ${ }^{3}$, atravessando a Idade Moderna, e desta até chegar à contemporaneidade.

$$
\text { A transição }{ }^{4} \text { entre a }
$$

modernidade e a contemporaneidade influenciou $\mathrm{O}$ pensamento da pósmodernidade no final do século XX e todo o século XXI, resultando em uma revolução paradigmática emergente, ou de vários paradigmas emergentes, apontando novos olhares para espaço, tempo e velocidade.

\section{O bólon espacial, cujo desenho} das práticas sociais tornou-se cada vez mais complexo, imediatista e veloz, exigindo movimentos ininterruptos nas relações humanas e na inovação do conhecimento.

O tempo passa a ser instantâneo e a informação descartável, o novo torna-se "velho" à medida que nos movemos com a tecnologia na busca pela satisfação, motivados por uma obsessiva vontade de viver a sensação

substância material passa pelas transformações, emergindo e retomando em seus princípios materiais para os átomos em duas divisões: as formas (figura, ordem e posição) e as estruturas das "coisas", decorrente do movimento dos átomos no vazio. Posteriormente, analisou a matéria em Aristóteles na relação entre forma e matéria, destacando que, "a matéria não é uma realidade por si mesma, mas só uma possibilidade, uma potentia; somente a forma lhe dará existência" (Werner HEISENBERG. Física e filosofia: 1995, p. 113). W. Heisenberg observou em Descartes que a divisão entre "res extensa" e "res cogitans", não permaneceria no século XIX, pois a relação entre os diferentes elementos da matéria na física e seu processo de transmutação pelas descobertas da radioatividade, em 1896, por Becquerel e, levadas adiante pelo casal Curie, criariam outras relações para mente e matéria, forma e matéria, corpúsculo e onda, sendo descobertas e desenvolvidas na física quântica durante o séc. XX.

${ }^{3}$ Para G. Gusdorf, se o conhecimento da ciência durante a Idade Média sofreu o rechaçamento do pensamento do prazer, provando ser em si mesma uma busca insaciável do bem-estar, como uma roda que gira ao redor de seu próprio eixo indefinidamente, cujo resultado da satisfação se encontra em produtos das construções epistemológicas e tecnológicas, sujeita ao movimento de sua velocidade, de sua aceleração, imersas nas necessidades e desejos do homem, sobretudo, ao responder a lista de anseios do homem na era da pósmodernidade.

E. Morin, no paradigma da complexidade refere-se a um conjunto de fenômenos correlacionados: A relação é simultaneamente complementar, concorrente, antagônica, recursiva e hologramática entre estas instâncias co-geradoras do conhecimento. (Morin, p.19: 1991).

Portanto, emerge da
complexidade o novo paradigma sem
necessariamente estar condicionado a um
conjunto de regras e procedimentos existentes,

medieval, então os imaginários míticos e simbólicos, por sua vez, passaram pela banalização do pensamento cientificista na modernidade. Portanto, a transição paradigmática criou o conflito entre o mythos espacial religioso e o logos espacial científico. Observamos que o painel histórico versou tanto da razão aristotélica sobre a distinção entre essência e existência, revista na Suma Teológica de Santo Tomás de Aquino, como dos princípios e métodos científicos de Copérnico, Kepler e Galileu a Descartes e Newton: criando a tensão entre a concepção mítico-religiosa e o método-científico. (G. GUSDORF. Mito e metafísica: 1980).

${ }^{4}$ Neste aspecto, Thomas Kuhn, discute na teoria do paradigma, a revolução na ciência, durante o percurso histórico, acontecendo entre cisões e revoluções, mas os novos paradigmas surgem dos antigos, carregam parte do vocabulário, técnica e manipulação; contudo, determinados termos, conceitos e experiências do antigo paradigma acabam criando relações inovadoras entre si. (Thomas KUHN. A estrutura das revoluções científicas: 1989). 
ou aos problemas formatados de uma suposta solução $^{5}$, mas de relações sócio-culturais, políticas, epistemológicas e tecnológicas que se entremeiam.

Ao situarmo-nos no sistema de complexidade de base moriniano, incorporamos a ideia de caos para o processo de antidifusão ${ }^{6}$. Passamos da era da certeza à era da incerteza e indeterminação, compreendendo outra relação entre equilíbrio e caos, corpo e mente, matéria e onda, materialismo e metafísica. Nessa relação vemos a formação holotrópica dos fenômenos da natureza e das manifestações cíclicas do pensamento - criação/destruição/manutenção - para o conjunto de processos do paradigma da complexidade ${ }^{7}$ uma espécie de roda d'água do paradigma pós-moderno, que não se caracteriza pela finalidade da mera renovação, mas sua permanente insurgência do espaço e tempo newtoniano, ou mesmo das relações sociais solidificadas pelo controle e

\footnotetext{
5 O Teorema da Incompletude de Gödel contribuiu substancialmente para a revolução do pensamento. O teorema afirma que: "Dentro de qualquer sistema formal de axiomas, como a matemática atual, sempre persistem questões que não podem ser provadas nem refutadas com base nos axiomas que definem o sistema. Em outras palavras, Gödel mostrou que certos problemas não podem ser solucionados por nenhum conjunto de regras ou procedimentos". (Stephen HAWKING. O universo numa casca de noz: 2002, p. 139).

${ }^{6}$ Este conceito é desenvolvido, na Teoria das Estruturas Dissipativas, de Ilya Prigogine: "A atividade produtora de entropia não pode ser identificada com um simples nivelamento das diferenças. Sem dúvida, o fluxo térmico desempenha esse papel, mas o processo de separação dos gases misturados que se produz por acoplamento com a difusão é, por sua vez, um processo de 'antidifusão' que há uma contribuição negativa à
}

previsibilidade que havia no capitalismo clássico e na maneira como o pensamento cartesiano se estruturou.

O bólon aparece como uma proposta de totalidade concreta ou de totalização concreta, tal que se pode apreender o todo presente em cada parte, vislumbrandoo e reconstruindo-o, e as partes diferenciadas no processo de totalização; razão pela qual se supõe uma transdiciplinaridade, um conjunto de invasões territoriais, uma ontologia da contraditorialidade e uma abordagem compreensiva dos processos interrelacionados.

O termo hólon é retomado, por Arthur Koestler, dos antigos gregos "para se referir a uma entidade que é um todo e, ao mesmo tempo, uma parte de outro todo". (WILBER:1995, p.38). Edgar Morin discute a recursividade do todo e da parte para uma relação de interdependência em anel aberto de recursividades. Observamos que a relação

produção de entropia nele". (Ilya PRIGOGINE e I. STENGERS. Entre o tempo e a eternidade: 1992, p. 53 - 54).

7 “Desde Collingwood até Kuhn, o paradigma significa a 'estrutura absoluta de pressuposições' (...) São, assim, quadros que determinam os atos cognitivos e que, após a gradativa formulação e a constituição da 'comunidade científica', e as conversões operacionais (...), tendem a apresentar um caráter inconsciente, nas suas determinações, podendo assim se constituir como um obstáculo à comunicação e aprendizado, reduzindo a incidência das fantasmatizações no grupo; em profundidade, propicia as condições para a elaboração de um discurso verdadeiramente crítico". (José Carlos de PAULA CARVALHO. Antropologia das organizações e educação: um ensaio holonômico. Tese de Livre-Docência. USP: 1989 p. 16). 
perpassa pela temporalidade e espacialidade nas formas de luz e matéria - portanto, onda e corpúsculo (mais recentemente o físico Stephen Kawking levanta a questão do tempoespaço em multidimensões, em que a holografia codifica as informações de uma região do espaço para uma superfície com uma dimensão a menos - o número de estados internos de um buraco negro $)^{8}$. Assim, para este cenário a descoberta da holografia, por Denis Gabor, ocorre através da relação entre Objeto, Armazenamento de Onda e Construção da Imagem: "um registro congelado de padrões de interferência" (WILBER: 1995, p.34). Essa teoria impulsionou o neurofisiologista Karl Pribram a desenvolver a teoria holográfica neural, na qual cada neurônio apresenta-se como um hológrafo, possibilitando a descoberta de imensos conjuntos de hologramas neurais, espalhados por todo o encéfalo humano. O cérebro em Pribram conteria a fórmula do tempo e do espaço multidimensional. ${ }^{9}$

\footnotetext{
${ }^{8}$ Para o modelo de p-branas - objetos estendidos em "p" dimensões, como possíveis espaços-tempos com 10 ou 11 dimensões - "A holografia seria a correspondência de um para um entre estados em nosso mundo quadridimensional e estados em dimensões superiores". (Stephen HAWKING. Op. Cit: 2002, p. 198).

9 Segundo K. Pribram: "Os impulsos nervosos são gerados dentro dos neurônios e são usados na propagação dos sinais que constituem as informações ao longo de grandes distâncias, através dos sinais de extensas fibras nervosas. As variações de potencial, locais e graduadas, isto é, as ondas, ocorrem nas extremidades dessas fibras nervosas, onde elas se ligam a ramos mais curtos que formam uma rede de interconexões entre neurônios" (grifo nosso). Ibidem: 1995 , p. 35.
}

Segundo Edgar Morin, o cérebro humano ainda é juvenil e inacabado, e em suas conexões, cria relações no sistema espaçotemporal de multiplicidades, caos, integração, concorrência, antagonismo e reconciliação. $\mathrm{O}$ que nos devolve ao conceito de hólon.

Hólo-s do grego significa totalidade - e nomia - arranjo, manejo; e do correlato nómos - lei - e némein - distribuição das partes, constituindo assim a palavra holonomia. Para esse termo, podemos encontrar o tempo e o espaço, a respeito da ideia de uma totalidade na conformação das partes, elaboradas dos elementos que abrangem conjuntos complexos para o espaço infinito. Sendo reorientados para ultrapassar os conceitos de tempo e espaço absolutos newtonianos ${ }^{10}$.

Para Félix Guattari, não basta gerarmos uma geometria fractal, mas antes uma ontologia fractal ${ }^{11}$.

Nesse sentido, estaríamos na pós-modernidade trocando informações em uma sociedade do fractal? $\mathrm{E}$ as informações se

10 As três leis de Newton publicadas na obra Mathematical Principles of Natural Philosophy em 1687, estabeleceram as relações da base da mecânica clássica como o espaço absoluto e o sistema inercial. Assim, Newton desenvolveu um sistema que estabeleceu referências absolutistas, em outras palavras, um valor universal, uma relação constante para todas as variáveis, concebendo assim um universo temporal e espacial em valores absolutos dados pela mecânica clássica.

11 Trata-se de processos criadores de um infinito de focos autopoiéticos, de entidades virtuais, de dobras de espaço, desterritorializado, de agenciamentos mutantes, produzindo infinitos, produzindo atratores de criatividade social, gerando atualizações, gerando novas práticas sociais. (Félix GUATTARI. Caosmose: um novo paradigma estético: 2000). 
assegurariam em sistemas dinâmicos organizados? Ou a troca indefinida virtual de informações se relacionaria com a quantidade e a escala de ampliação de cópias das informações contidas dentro dela mesma, desde que revele novas informações? Estaríamos tratando de uma complexidade infinita ao nos socializarmos na rede mundial?

E. Morin coloca que há uma formação intensa do conjunto de forças paradigmáticas da complexidade, no que se refere à natureza de seus elementos antagônicos, complementares

e reconciliadores. ${ }^{12}$ Os fenômenos ocorreriam de diversas formas, manifestando-se simultaneamente e de diferentes modos.

O tempo-espaço compreenderia as incertezas e as expressões caóticas da linguagem no ambiente virtual; enquanto a velocidade transformaria informações na rede mundial em produtos da cultura, o conhecimento passaria a ser visto como um fenômeno de troca na sociedade da informação fractalizada.

O paradigma da complexidade é uma holoespistemologia, uma episteme que se atualiza na velocidade das transformações do conhecimento, interagindo em suas diferenças, complementando-se e reconduzindo-se a outros conhecimentos, criando um mosaico de

12 “(...) a manutenção de um antagonismo no seio de uma complementaridade é uma condição de fecundidade em matéria de complexidade. O conhecimento complexo necessita do diálogo em anel ininterrupto das aptidões expressões da sociedade virtual: a criação de expressões fractais socializada.

\section{Consideramos}

quatro

características que implicam nessa correlação entre os elementos opostos, complementares e de recondução no paradigma da complexidade para a pós-modernidade:

$1^{\circ}$ os elementos não se excluem em suas diferenças, antes são inclusos e se complementam para a existência em comum;

$2^{\circ}$ as transformações estão marcadas pelo movimento, portanto a criação é movimento em seus antagonismos e na recondução das informações;

$3^{\circ}$ a velocidade e o movimento são levados às últimas consequências nas relações sociais virtuais e na concepção do "novo", sendo um produto da cultura que descarta o "velho" e prima pela velocidade das transformações, e

$4^{\circ}$ não há um fim do caminho que percorremos apenas um processo contínuo de mudança permanente e inesgotável.

No Tao Te King, de Lao Tse, o tempo é, simultaneamente, enquanto não o é. A complexidade metafísica cria a sutura entre elementos antagônicos, que, através do Tao, transcendem as linearidades temporais e espaciais, em que avançar e chegar além

complementares/concorrentes/antagonistas, que são análise/síntese, concreto/abstrato, intuição/cálculo, compreensão/explicação". (Edgar MORIN. Op. Cit: 1991, p. 6). 
significa retornar, para entender e fazer cumprir a perfeição do Tao, enquanto movimento cíclico no universo. Nesse sentido, circunscreve-se o movimento infinito e, no mover cíclico em direção ao plano de imanência deleuzeano, o movimento infinito definido na sua ida e volta só é possível ir, se este retorna sobre si mesmo, a dobra de um sobre a dobra de outro. ${ }^{13}$

"Há algo natural e perfeito".
Existentes antes de Céu e Terra
Imóvel e insondável
Permanece só e sem modificação
Está em toda parte e nunca se esgota
Não conhecendo seu nome, chamo-o Tao
Obrigado a dar-lhe um nome,
O chamaria Transcendente
Transcendente significa avançar
Avançar é chegar acolá
Chegar acolá quer dizer retornar". (Lao Tse:1995,
p.67).

E. Morin apresenta no sistema de complexidade de base, o movimento da relação em um jogo ativo e complexo, e afirma que o pensamento complexo movimenta-se dentro do sistema-energia e na complexificação do potencial hologramático.

A comunicação expande-se na multiplicidade do tempo-espaço, que se interrelacionam em movimento para suas conexões através das trocas, agenciamentos e

13 Gilles DELEUZE e Félix GUATTARI. $O$ que é filosofia?: 1993. multiplicidades heterogêneas, descontínuas, indeterminadas e infinitas.

Manifesta-se no espaço a multiplicidade dimensional, que para a expressão da simultaneidade constroem o desconstrutivismo, descontinuam a continuidade, como um conjunto complexo de bólons de partículas, que se iniciaram de um encantador caos e buscam em si a reorganização do sistema.

Nesse enfoque, M. Wertheim relaciona a geometria não-euclidiana com o hiperespaço, visto na obra literária Neuromancer, de William Gibson. De acordo com a ótica de Wertheim, o imaginário de um locus que reúne pessoas no espaço virtual e troca informações digitais propõe que adentremos em dimensões não-físicas e nos projeta em um espaço pulverizado por energias pensantes, saltando em estado de quantum de energia da comunicação em territórios de ciberdimensões na Internet.

Ken Wilber desenvolve alguns princípios elucidativos para o conceito de bólon e amplia a discussão sobre esse tema, aprofundando e estendendo suas concepções sobre uma maior compreensão de seus conceitos. Por exemplo, o princípio de que o Kosmos é composto de bólons, os quais mantém a sua totalidade e sua partição. Nessa relação da totalidade com a parte, os hólons possuem uma ação, uma determinada autonomia, uma 
condição para manter a sua totalidade sobrevivendo às variáveis que interferem em suas existências.

As comunidades virtuais dos hólons são preservadas e a ação sobre esse conjunto impede a dissolução dos bólons em sub-hólons, evitando o seu desaparecimento, já que os hólons convivem em um paradoxo: quando não conseguem manter suas comunidades e sua ação, decompõem-se em sub-hólons, experimentando assim o estado de autodissolução; mas poderá ocorrer que os bólons evoluam, atingindo aquilo que Ken Wilber denomina de "autotranscendência".

Um jogo entre a vida e a morte, um processo de acontecimentos para a transmutação e eliminação, como também um lançamento para o infinito. Segundo Gilles Deleuze e Félix Guattari: "O pensamento reivindica 'somente' o movimento que pode ser levado ao infinito. O que o pensamento reivindica de direito, o que ele seleciona, é o movimento infinito ou o movimento do infinito. É ele que constitui a imagem do pensamento" (DELEUZE e GUATTARI: 1993, p. 53).

Henri Bergson entende o pensamento intuitivo como a busca imediata do eterno. O infinito é aquilo que concebe

\footnotetext{
${ }^{14}$ Para Henri Bergson: "Seria preciso acrescentar os termos desta multiplicidade, em lugar de se distinguirem como os de uma multiplicidade qualquer, penetram uns nos outros, que podemos, sem dúvida, por um esforço de imaginação, solidificar a duração uma vez escoada e dividi-la então em pedaços que se justapõem e contar
}

vetores de infinitas destinações, sem um ponto de partida ou a necessidade de um fim no caminho, trata-se do movimento em percurso intuitivo. Assim, tendendo ao absoluto, preenchido pelas dobras que se multiplicam e incluem uma dobra sobre outra dobra, um jogo elaborado por movimentos infinitos de dobras atemporais e aespaciais: como uma performance holográfica no universo. Poderíamos denominá-los de elementos da imanência.

Vale destacar que no plano da imanência:

$$
\begin{aligned}
& \text { "Cada movimento percorre todo o plano, fazendo um } \\
& \text { retorno imediato sobre si mesmo, cada um se dobrando, } \\
& \text { mas também dobrando outros ou deixando-se dobrar, } \\
& \text { engendrando retroações, conexões, proliferações, na } \\
& \text { fractalização desta infinidade infinitamente redobrada" } \\
& \text { (Gilles DELEUZE e Félix GUATTARI: 1993, } \\
& \text { p. 55). }
\end{aligned}
$$

$$
\text { Portanto, essa multiplicidade }{ }^{14}
$$
não se parece com nenhuma outra, é singular, pois sendo movente torna-se mutável, por isso se justifica que o movimento humano é inesgotável, tende à infinita criação, ao excesso dos atos do movente, às ações tendendo às últimas consequências do movimento; porém sem encontrar um fim no caminho. Será o

estes pedaços, mas que esta operação se realiza sobre a lembrança fixada da duração, sobre o traço imóvel que a mobilidade da duração deixa atrás de si, não sobre a duração mesma". (Henri BERGSON. Introdução à metafísica: 1979, p. 19). 
processo que irá impulsionar o movimento e o movimento criará o processo: uma ligação indissociável.

A transformação e a novidade na pós-modernidade, são ideias que vem com a velocidade, com o movimento; mas se o movimento tende ao infinito para que haja transformações, e estas se constituem naquilo que denominamos "novo"; então, estamos jogando com as transformações e o movimento até às últimas consequências das mudanças com a velocidade, até que o "novo" ameace entrar em colapso, mas para não chegar à sua disfunção cria novas regras de funcionamento do sistema, poupando a inovação e o movimento de seu completo esgotamento.

Apesar de tender ao absoluto, esse retorno da imanência sobre si mesmo, em dobras conectadas e difundidas, possui unidade própria, reconstitui o bólon a um plano de consistência, ao projetar a memória em narrativas, linguagens e expressar os elementos representacionais e as forças culturais do Devir Ser. Do Ser que está em processo inacabado. Todavia, regado por novos conceitos paradigmáticos, novas regras para continuar existindo, ou passando pelo processo de mudança.

O hólon traz em si os elementos de profundidade e de amplitude, enquanto pilares de seus princípios para a formação holográfica, criando com a holografia dimensões adicionais à realidade.
Dessa forma, quando há a experiência de uma maior profundidade holográfica, significa que menos são os hólons que atingem aquela profundidade e consequentemente mais complexa e profunda a consciência se torna na relação com os níveis de aprofundamento de si mesmo. Na visão de Gilles Deleuze e Félix Guattari: “Um agenciamento em sua multiplicidade trabalha forçosamente, ao mesmo tempo, sobre fluxos semióticos, fluxos materiais e fluxos sociais. Um agenciamento põe em conexão certas multiplicidades tomadas em cada uma destas ordens”. (DELEUZE e GUATTARI. Mil platôs vol 1: 1995, p. 19).

A multiplicidade e a unicidade existem e fazem sentido se existirem conexões ligando os fluxos que se codificam, de modo que o desdobramento em fluxos possa ampliar-se, ao mesmo tempo, em que adquirem profundidade holográfica para outras realidades criadas. Os bólons conectamse em um processo de estados moventes, complexificando a consciência, que desafia os limites do movimento e impede o esgotamento dos fenômenos moventes: a transformação é um processo, não um fim em si mesmo.

$\mathrm{O}$ agenciamento do hólon nas partes que constituem processos de comunicação refere-se ao múltiplo da sua totalidade, como elementos comunicáveis, sistemas representacionais de linguagem, criando o movimento de sua própria formação. O projeto de imanência, no sentido deleuzeano é caos e movimento, caos porque 
desestabiliza a ordem das coisas, e movimento porque o mover provoca a mudança, cria o projeto de imanência, torna a imanência projeto de comunicação, atribuindo significação ao bólon e produzindo um mosaico de fluxos de energia na experiência holonômica.

\section{No Paradigma do Universo Digital}

A memória eletrônica conecta coletivamente a quantidade de informações arquivadas pela inteligência artificial das máquinas. $\mathrm{O}$ conceito de inteligências conectadas de Derrick de Kerckhove aborda que o pensamento humano ao expandir a mente na rede mundial, possibilita a criação de uma nova condição cognitiva. A energia mental compreende uma camada do pensamento espalhada pela rede da Internet como apropriação coletiva da energia pensante e pulveriza-se no ciberespaço, criando um fluxo energético mental coletivo ${ }^{15}$.

Ao observarmos esse conceito levantamos os seguintes questionamentos: Qual é o real sentido da memória eletrônica para o locus midiatizado tecnológico, para as narrativas textuais, imagéticas e sonoras na web? O fluxo do pensamento da comunidade virtual movimenta as linguagens por toda a rede mundial no espaço telemático interagindo com o pensamento dos usuários? Estamos criando uma nova história com as narrativas digitais na pós-modernidade, através de inteligências conectadas ou apenas estamos retomando nossas referências culturais com as antigas matrizes culturais? A partir da ideia de uma circulação de energia pensante, há um novo diálogo entre as tradições e a contemporaneidade no espaço telemático ou repetimos os mesmos modelos que herdamos, adaptando-os a um ciberespaço?

$$
\text { Para essas questões, procuramos }
$$
discutir a camada pensante no espaço telemático em sua multiplicidade e interatividade, ao produzir não apenas uma única escritura, antes fluindo no imaginário de multiescrituras nos links e nas produções textuais, icônicas e sonoras digitalizadas.

Nesse aspecto, T. Chardin considera a evolução humana tanto em termos intelectuais (cognitivo) como espirituais (metafísico) e aponta a existência de duas energias no universo: a energia radical e a energia tangencial (a energia radical corresponde ao conceito de força newtoniana de causa e efeito e a energia tangencial é interna de caráter metafísico).

$$
\text { A energia tangencial }
$$
corresponde a três camadas de energia: dos objetos inanimados, dos seres vivos e da consciência humana. A consciência do homem, que nos interessa para este estudo, habita no pensamento reflexivo, em uma

15 Derrick de KERCKHOVE apud Diana DOMINGUES: 2002, p. 140.

324 FERNANDES, E.: Paradigma Emergente (Hólon) e o Movimento do Pensamento na Pós- 
camada pensante humana. Chardin denomina a camada da consciência humana de Noosfera $^{16}$. O que se considera um estágio evolutivo do pensamento, o mesmo que manifesta o processo de transformação, valoriza a velocidade das informações e prioriza o novo. A Noosfera altera as regras quando o limite e as barreiras de sua evolução a ameaçam, ou quando o processo da mudança está intimidado pelos riscos das disfunções em suas transformações.

Ao partir do princípio que a Noosfera é uma energia psíquica, mental, uma esfera da reflexão, da criação consciente, da camada pensante e se a concebermos espalhada pela rede na web da pósmodernidade, como fenômeno do espírito humano, essa Noosfera dissemina-se digitalmente, cruzando-se com outras Noosferas, recebendo informações e emitindo energias em forma de dados e arquivos, processando informações. Portanto, a relação midiática internarrativa configura a narrativa, sobretudo, para uma Noosfera que circula informações ao expandir-se como uma Noogênese para o conceito teilhardiano: uma esfera derivada da complexidade da consciência, oriunda na origem do espírito humano, a qual narra o pensamento e a energia em um estado de mutabilidade, o que lhe serviria de garantia para a construção das identidades coletivas e individuais,

\footnotetext{
${ }^{16}$ Etimologicamente, o termo "Noosfera" junta, à raiz grega noûs (espírito, psique) à sphaera (esfera). Portanto, o neologismo de Chardin significa a camada
}

movimentando-a em forma de dados que circulam na rede mundial em uma consciência coletiva.

\section{Para André Lemos: "O} cyberespaço é uma Noosfera na medida em que ele é uma camada abstrata e invisível, pela qual circulam dados, imagens, espectros e fantasmas digitais. Esse cyberespaço-Noosfera está em via de expansão planetária como um tipo de consciência coletiva" (LEMOS: 1999, p. 7).

A rede mundial, ao pensar de forma coletiva, integra no sistema seus múltiplos nós e links entrelaçados no labirinto do ciberespaço. A Noosfera no ambiente virtual caracteriza-se como um sistema de energia pensante coletivo. Portanto, o pensamento virtual na cibercultura configura um sistema inteligente que reúne as inteligências humanas e artificiais. As narrativas das inteligências coletivas e das tecnologias da inteligência identificadas nos sistemas computacionais, que impulsionam a circulação da Noosfera produzida pela informação e pela sociabilização das comunidades virtuais. Observa-se então, que o deslocamento das narrativas na internet, configura-se como um fenômeno da comunicação planetária, em que a transformação se consolida nessa comunicação. As ideias do novo e da evolução são interdependentes das novas tecnologias.

pensante humana, refletida na união do material e espiritual. (T. CHARDIN. O fenômeno humano: 1995, p. 196-198). 
O sistema de troca e de processamento das informações, ao quantificar e qualificar a energia produzida no território da telemática agencia nossos pensamentos e sentidos. A comunicação entre computadores está ligada à rede universal, em que sistemas comuns das máquinas tecnológicas servem de migrações para uma grande quantidade de bancos de dados; pois, o sistema está integrado à mesma energia em forma de dobras, móvel, mutável, nômade e fluida. Nesse sentido, o digital em processo de transformação no movimento de circulação integrada, transmuta a energia pensante em rede digital conectada no ciberespaço.

Disso pode-se concluir que: a Noosfera humana como camada pensante do ciberespaço, encontra-se na memória artificial das inteligências coletivas na web, criando à concepção de evolução do modelo de pensamento pós-moderno inter-relacionada entre homem-máquina. $O$ pensamento estará evoluindo segundo as relações em que o homem criará, ao longo dos anos com os sistemas inteligentes de máquinas, aplicativos e comunicações digitais.

Pierre Lévy ao levantar o significado da rede ou o valor contido na cibercultura, encaminha essa mídia à universalidade de interconexões, concebida como o receptáculo de inteligências coletivas das informações, das máquinas e dos

\footnotetext{
${ }^{17}$ Pierre LÉVY. Cibercultura: 1999, p. 113.

${ }^{18}$ André LEMOS. Op. Cit: 1999, p. 7.
}

homens ${ }^{17}$. A internet circula sua energia universal conectada e ilimitada na rede mundial, tornando suas formas e conteúdos condicionados a um pensamento de caráter universal, evitando localizar-se como informação sedentária, antes se configura como informação nômade, em movimento permanente, deslocando-se, passando de uma máquina a outra, de um usuário a outro e entre usuários-máquinas, enquanto locus de comunicação virtual.

André Lemos observa que o ciberespaço da Noosfera encontra-se em expansão planetária, formando uma consciência coletiva, pois as informações circulam no próprio infinito da Noosfera coletiva $^{18}$.

Então, por que a Noosfera migrou ao ciberespaço da internet, produzindo linguagens textuais, imagéticas e sonoras interconectadas à rede mundial? A camada pensante coletiva na internet circula pelo espalhamento na rede, conectando a coletividade ao espaço fluido de comunicação no meio eletrônico, a realidade virtual, a realidade em potência: um espaço em potência não limitado - heterogêneo e múltiplo. $O$ nômade usuário da rede mundial desterritorializa territórios, para então reterritorializar outros espaços, portanto, um espaço perene, um ápeiron ${ }^{19}$ do ciberespaço na rede mundial.

${ }^{19}$ Ápeiron é uma palavra de origem grega que significa o não limitado, sem fim, imenso, ilimitado, inumerável, 
$\mathrm{O}$ conceito de ápeiron, de Anaximandro de Mileto, da Escola Jônica, compreende um espaço infinito, em que o pensamento flui em um meio não limitado; pois a camada do pensamento circula em um espaço de transitoriedade, interconectada ao pensamento de uma coletividade, expandindo uma consciência coletiva, mas movido por infinitos planos.

Para Margaret Wertheim, o ápeiron exigiu do Renascimento uma mudança paradigmática sobre a concepção de espaço infinito, sobretudo, da teologia cristã. Entretanto, entre os séculos XVI e XVII, vários pensadores procuram fundar e justificar o espaço infinito enquanto espaço divino. Portanto, se essa compreensão representou um preço muito alto ao cristianismo, e exigiu do Iluminismo uma mudança contundente do seu entendimento sobre o espaço, após tantos séculos, a realidade virtual e o universo do digital abandonam concepções lineares de dimensões espaciais e assumem um espaço, que não mais se torna circunscrito ao físico ou espiritual, mas de certa forma estão envoltos nas relações de antinomia para homem e máquina, onda e corpúsculo, realidade simulada e fisicalidade, razão e espiritualidade, off-line e on-line, grafia e holografia, memória artificial e memória humana, analógico e digital.

incalculável, interminável, indeterminado. Portanto, o prefixo "a" de negação com o "péras" de limite, término, fronteiras formam a origem do que há na phýsis, isto é, na natureza do perene, do transitório, da eternidade.
Pois ainda assim, torna-se necessário redimensionar o ápeiron de Anaximandro para o ciberespaço, capturado pelas inteligências artificiais do espaço virtual, sobretudo ao constituir em outra forma paradigmática de pensar coletivamente $\mathrm{O}$ espalhamento do pensamento na rede mundial, e estabelecer relações para um ciberespaço cartografado e não limitado.

Para Anaximandro, a natureza não é nenhuma qualidade determinada ou mesmo definida, antes a relação entre $p h y j s i s^{20}-$ natureza - e ápeiron define o princípio e o elemento de todas as coisas no mundo, existindo na forma de ilimitado, infinito, incalculável, imenso e indeterminado. A criação da vida para Anaximandro ocorre não através dos elementos individuais, como terra, água, ar, fogo, úmido, frio, seco e quente, mas pela dissociação que separa os contrários gerados pelo eterno movimento.

Assim, os elementos ao serem separados do princípio, criam em si a multiplicidade como forças contrárias, para então retornar ao princípio. Portanto, se a criação é gerada pela relação dos opostos, segundo Anaximandro, então o devir é o movimento desse conflito dos contrários, e

\footnotetext{
20 A palavra grega "phýsis" é o fundo inesgotável de onde vem o kósmos, o fundo perene para onde regressa todas as coisas, a realidade primeira e última de todas as coisas.
} 
será no ápeiron a proto matéria ${ }^{21}$ reincorporada como elemento transmutado da energia pensante em forma de multiplicidade ${ }^{22}$.

Observamos que a Noosfera ao atravessar o ápeiron, o faz não sobre um mesmo plano, mas a partir de uma multiplicidade de planos, que potencializam os horizontes infinitos, desempenhando movimentos fluidos, planos que se desdobram em dobras infinitas, em infinitos platôs na multiplicidade de dimensões do ápeiron. Para a memória eletrônica o espaço infinito manifesta-se, como sendo indeterminado, ilimitado, efêmero e a-dimensional, conectando-se tanto pela mente dos usuários na web como pelas inteligências artificiais, como: software, hardware, robôs, arquivos e banco de dados eletrônicos.

Enquanto transformação da camada pensante no espaço virtual, o princípio de vir a ser gera a desterritorialização no ciberespaço, e, portanto, uma memória eletrônica mutável e nômade com textos, imagens e sons que se desfazem e refazem: os conteúdos e as formas no ciberespaço permanecem em constantes re-atualizações movidos pelo princípio de perenidade e de velocidade da informação, do conhecimento e da linguagem.

\footnotetext{
${ }^{21}$ O Ser puro ou a existência pura, destituída de forma, é uma matéria especial, a proto matéria, ontologicamente anterior à matéria prima sensível de Aristóteles.
}

Segundo Pierre Lévy: "O território cartografado ou simulado pelo mundo virtual não é necessariamente o universo físico tridimensional. Pode dizer respeito aos modelos abstratos de situação, o universo de relações, o complexo de significações, o conhecimento, os jogos de hipóteses, até mesmo as combinações híbridas de todos estes territórios” (LÉVY: 2002, p.72).

A Noosfera na realidade virtual possui o significado de uma potência cartografada de imersão e de navegação ${ }^{23} \mathrm{sem}$ ser um fenômeno localizado espacialmente, o movimento e as transmutações permanentes caracterizam um eterno vir a ser. O ilimitado território que a camada da Noosfera se atualiza e transforma-se, presentificando no devir de códigos do ciberespaço.

O pensamento ao situar-se no espaço telemático por toda a extensão da rede mundial eletrônica combina teorias, ideias, produções, performances, experiências de inúmeros usuários virtuais. De modo que, textos, imagens e sonorizações digitalmente editados representam as escrituras tecnológicas que se cruzam e formam as novas linguagens do homem pós-moderno.

$\mathrm{O}$ vir a ser não se configura como imitação nem semelhanças, mas como verificamos no pensamento deleuzeano:

\footnotetext{
${ }^{22}$ Marilena CHAUI: 2002 , p. 58-62.

${ }^{23}$ Pierre Lévy. Cibercultura: 2002.
} 
"Captura de código, mais-valia de código, aumento de valência, verdadeiro devir, devir-vespa da orquídea, devir-orquídea da vespa, cada um destes devires assegurando a desterritorialização de um dos termos e a reterritorialização do outro, os dois devires se encadeando e se revezando segundo uma circulação de intensidades que empurra a desterritorialização cada vez mais longe" (DELEUZE, GUATTARI: 1995, p.19).

\section{A linguagem virtual não} pertencendo a um ponto central do território, ou sequer se fazendo representar por elementos fronteiriços, apresenta-se espacialmente nas significações como um devir do território. Na visão de G. Deleuze, o território é um devir à medida que ele é um processo do próprio território inacabado ou o território desterritorializado, quando há a experiência do deslocamento territorial no espaço. Desterritorializa-se de forma nômade, porque o nômade é por natureza desterritorializado, cartografando o território, mapeando as mudanças nas fronteiras ${ }^{24}$.

Após um longo período para o pensamento integralizar-se na revolução do espaço telemático, ocorre um complexo processo de mutação paradigmática, voltada aos conceitos de multiplicidade, de acentrismo, de heterogeneização, de coletividade, de um "eu" isolado para o "nós" na rede, da

\footnotetext{
24 "Para o nômade, é a desterritorialização que constitui sua relação com a terra, por isso ele se reterritorializa na própria desterritorialização. É a terra que se desterritorializa ela mesma, de modo que o nômade aí encontra um território". (Gilles DELEUZE e Félix GUATTARI. Mil platôs. Vol. 5: 1998, p. 53).

${ }^{25}$ Pierre LÉVY. As tecnologias da inteligência: 1993, p. 110.
}

transformação do pensamento e da linguagem, do analógico e digital, do estruturalismo e pósestruturalismo, do texto e hipertexto digital, da textualidade intertextualidade/pluritextualidade.

A interatividade no paradigma da cibercultura é um componente fundamental, porque cria a possibilidade da sociabilização das comunidades virtuais, sobretudo quando tecnicamente conectam a memória aos terminais inteligentes ou mesmo às informações que se encontram disponíveis na rede com acesso à comunidade mundial ${ }^{25}$. $\mathrm{Na}$ visão de Derrick de Kerchkove, a interatividade pode ser traduzida como toque. ${ }^{26}$ A narrativa na internet só pode ser interativa se explorarmos o acesso às informações, mas implicando na interação dessas informações entre os usuários do digital, utilizando múltiplas operações infoculturais, ao compartilhar o espaço na rede, principalmente se as redes são concebidas como prolongamento do toque dos dedos no tempo real em uma proporção mundial. ${ }^{27}$

O tato é a voz de comando que abre o mundo para o ambiente virtual, transmite informações, reconduz informações, produz e distribui informações. O toque é a

\footnotetext{
${ }^{26}$ Derrick de KECKHOVE. Connected Intelligence The arrival of the web society. In: Somerville House Publishing a divison of Somerville, House Books Limited.

${ }^{27}$ Diana DOMINGUES. A Caixa de Pandora e as tramas da vida nas redes telemáticas. In: Maria Beatriz de MEDEIROS (org.). Arte e Tecnologia na Cultura Contemporânea: 2002, p. 141.
} 
extensão da mente de uma Noosfera coletiva. O toque não mudou apenas o comportamento humano, mas os modos de pensar e os modos operantes de agir, destacando ainda mais a matéria pensante como produto de criação e produção de trabalho na sociedade, um produto abstrato, um produto que produz ideias.

Consideramos a concepção de que a interatividade evoca a memória compartilhada por pessoas na rede mundial, em forma de documentos digitais e programas conectados com os grandes terminais da web e criam a memória artificial nas tecnologias da inteligência.

A memória interativa da comunidade virtual tece um cruzamento com a memória das máquinas, sistemas e programas; então, o fenômeno da anámnesis ${ }^{28}$ atua na Ideia e na Forma da linguagem coletiva eletrônica - em um sentido platônico -, produzindo informações e programas inteligentes, porque as tecnologias inteligentes, dos programas e dos arquivos existentes reúnem a memória de toda a coletividade virtual, pelo processo de interatividade das memórias artificiais produzidas, arquivadas e distribuídas pelo toque dos dedos, uma relação que cria a comunicação entre o interno e o externo e a conexão das múltiplas memórias.

Estamos vivendo parte do processo da revolução paradigmática no

${ }^{28}$ A palavra "anámnesis", oriunda do grego, apresenta em Platão, a concepção do processo de conhecimento, universo da tecnocultura, construímos e desconstruímos alguns conceitos e princípios descobertos e, ainda, realizamos pesquisas no espaço telemático, como também experienciamos uma longa e processual transição de ideias e de operações metodológicas da ciência, do pensamento, da tecnologia e do conhecimento - se apresentando em um estágio inacabado (work in progress) -, o paradigma emergente continua refazendo-se e manifestando-se como linguagem digital, lembrando que, segundo Pierre Lévy, o digital surge como a "infraestrutura do ciberespaço" (Lévy: 1999, p.32). Conforme observamos em novas mídias de comunicação, sociabilização, comercialização, informação em que a velocidade da informação descarta o conteúdo informacional tão rapidamente, que pouco tempo nos resta para pensar e processar a informação, ou mesmo para consumir outros suportes e aplicativos, quando do surgimento de novas linguagens e sistemas, de novos métodos de conhecimento e de criações digitalizadas.

$$
\text { Assim, ao emergir em }
$$
permanentes pesquisas e experimentações científicas, tecnológicas, sociais e estéticas no ambiente virtual, a cultura tecnológica aponta para o paradigma da pós-modernidade como um novo desafio do homem no tempo da presentificação e da velocidade das transformações, em uma sociedade cada vez

fundada na lembrança das Ideias ou das Formas, em que a psique contempla o mundo das Ideias. 
mais pensada virtualmente, em que o pensamento se manifesta no toque dos dedos e o toque nos faz voltar ao pensamento.

\section{Referencias Bibliograficas}

1. BERGSON, Henri. Introdução à metafísica. In: LEOPOLDO, Franklin (org.). Henri Bergson. São Paulo, Abril Cultural, 1979.

2. CHARDIN, Pierre T. de. O fenômeno bumano. São Paulo, Cultrix, 1995.

3. CHAUI, Marilena. Introdução à filosofia: dos Pré-Socráticos a Aristóteles vol.1. São Paulo, Cia das Letras, 2002.

4. DELEUZE, Gilles e GUATTARI, Félix. Mil platôs. Vol. 1. Rio de Janeiro, Ed. 34, 1995.

5. . Milplatôs vol. 2. Rio de Janeiro, Ed. 34, 1997.

6. . Milplatôs vol. 3. Rio de Janeiro, Ed. 34, 1999.

7. Mil Platôs Vol. 4. Rio de Janeiro, Ed. 34, 1997.

8. Mil platôs. Vol. 5. Rio de Janeiro, Ed. 34, 1998.

9.

. O que éfilosofia? Rio de Janeiro, Ed. 34, 1993.

10. DOMINGUES, Diana. A Caixa de Pandora e as tramas da vida nas redes telemáticas. In: MEDEIROS, Maria Beatriz de (org.). Arte e Tecnologia na Cultura Contemporânea. Brasília, UNB/Dupligráfica, 2002, p.136-147.

11. FERNANDES, Edson. Estruturas mitopoiéticas e performance no espaço telemático. In: Memória ABRACE VII: Anais do III Congresso Brasileiro de Pesquisa e Pós-Graduação em Artes Cênicas. Florianópolis, Outubro/2003, p. 67-69.

12. GUATTARI, Félix. Caosmose: um novo paradigma estético. São Paulo, Ed. 34, 2000.

13. GUSDORF, G. Mito e metafisica. São Paulo, Convívio, 1980.

14. HAWKING, Stephen. O universo numa casca de noz: São Paulo, Arx, 2002.

15. HEISENBERG, Werner. Física $e$ filosofia. Brasília, Ed. Universidade de Brasília, 1995.

16. KECKHOVE, Derrick de. Connected Intelligence - The arrival of the web society. In: Somerville House Publishing a divison of Somerville House Books Limited. Toronto, Ontario, s/d.

17. O senso comum, antigo e novo. In: PARENTE, André (org.). Imagem Máquina. Rio de Janeiro, Ed. 34, 1993, p. $56-64$.

18. KUHN, Thomas. A estrutura das revoluções cientificas. São Paulo, Perspectiva, 1989. 
19. LAO TSÉ. Tao Te King. São Paulo, Attar, 1995.

20. LEMOS, André. As estruturas antropológicas do cyberespaço. bttp://facom.ufba.br/pesq/cyber/lemos/est ryyl.btml. Salvador, 1999.

Acesso em mar 2004.

21. LÉVY, Pierre. As tecnologias da inteligência. Rio de Janeiro, Ed. 34, 1993.

22. Cibercultura. Rio de Janeiro, Ed. 34, 1999.

23. O que é virtual. Rio de Janeiro, Ed. 34, 2001.

24. MORIN, Edgard. La méthode III: la connaissance de la connaissance. Paris, Sevil, 1985.

25. $O$ método $I V$ : as idéias. Lisboa, Europa-América, 1991.

26. PAULA CARVALHO, J. C. A antropologia das organizações e educação: um ensaio holonômico. São Paulo, 1989. Tese (Livre-Docência em Educação). Faculdade de Educação, Universidade de São Paulo, 1989.

27. PRIGOGINE, Ilya e STENGERS, I. Entre o tempo e a eternidade. São Paulo, Cia das Letras, 1992.

28. WERTHEIM, Margaret. Uma bistória do espaço de Dante à Internet. Rio de Janeiro, Jorge Zahar Ed., 2001.

29. WILBER, Ken. Uma breve bistória do universo. Rio de Janeiro, Nova Era, 2001.
30. WILBER, Ken (org.). O paradigma Holográfico e outros paradigmas. São Paulo, Ed. Cultrix, 1995. 